Whitehead, J. C. (2005) Combining Willingness to Pay and Behavior Data with Limited Information, Resource and Energy Economics, 27(2):143-155 (June 2005). Published by Elsevier (ISSN: 0928-7655).

\title{
Combining willingness to pay and behavior data with limited information
}

John C. Whitehead

\begin{abstract}
In order to incorporate behavioral change in the willingness to pay model we jointly estimate contingent valuation and revealed and contingent behavior data. The willingness to pay model includes the change in the number of recreation trips as an independent variable. Models that do not account for the endogeneity of trips produce inconsistent coefficient estimates.

Accounting for the endogeneity of the change in trips in both independent and jointly estimated models of willingness to pay and behavior leads to an increase in the ratio of use value to total value.
\end{abstract}




\section{INTRODUCTION}

The contingent valuation method (CVM) is used to estimate benefits from statements about willingness to pay for policies or programs (Mitchell and Carson, 1989). Empirical models of willingness to pay are typically used to describe the factors that affect willingness to pay. These are tests of the theoretical validity of willingness to pay when theory guides the empirical model. For example, in the recreation context, more avid recreationists should be willing to pay more for an improvement in the recreational opportunity. In the health context, mitigating behavior that influences the severity of illness should decrease the willingness to pay for avoiding illness.

As a direct test of this conjecture, Seller et al. (1986) propose a specification of willingness to pay for site access that includes recreation trips as an independent variable. In response, McConnell (1990) shows why a model of the willingness to pay for site access should not include endogenous variables, such as trips, as independent variables. The comparative static effect of the own-price on the willingness to pay for site access is equal to the number of trips. If trips are included in the model, the effect of the optimal number of trips on willingness to pay should be zero. This model also shows that willingness to pay for access and recreation demand can be jointly estimated.

Similar to McConnell (1990), Whitehead (1995) shows that willingness to pay for quality improvement is a function of own-price and not utilization rates. Empirical estimates of the effect of a change in the own-price can be used to identify the change in behavior from the quality improvement. Huang et al. (1997) implement this approach by jointly estimating the willingness to pay function, with own-price as an independent variable, and the change in the number of trips. Joint estimation of contingent valuation and contingent behavior models imposes theoretically consistent behavioral restrictions on willingness to pay models and may improve econometric efficiency.

Many applications of joint willingness to pay and behavior models will suffer from a lack of necessary data on a key variable. For example, in health economics applications the out-ofpocket costs of medical utilization may be (1) constant due to the law of one price or (2) difficult to measure due to differences in health insurance and other aspects of medical plans. In recreation economics the costs of recreational use may be (1) constant due to little variation in travel distances (e.g., from inadequate spatial sampling) and (2) measurement difficulties arising from differences in the opportunity costs of time, travel speed, and access point definitions (e.g., when air quality improvements lead to increased time spent outdoors), among other reasons. As an alternative to including exogenous cost variables in empirical models of willingness to pay, McConnell (1990) notes that the endogenous behavior variable can act as a proxy for price.

There are several recent examples of the use of endogenous variables in the recreation and health CVM literatures. Kinnell et al. (2002) include "number of ducks shot" and "time preparing for duck season" variables in a willingness to pay model of prairie pothole protection. Champ et al. (2002) include a variable for respondents who "buy products that are environmentally friendly even if they cost more" in a willingness to pay model for open space land purchases. Stewart et al. (2002) include a variable for whether the respondent is a daily smoker as a measure of health status in willingness to pay models for cancer, heart and community care programs. 
Whynes et al. (2003) include "visits to the dentist" and whether the respondent is a current smoker as measures of attitudes toward mitigating behavior in a willingness to pay model for colorectal cancer screening.

Endogeneity exists when the error term in the behavioral model is correlated with the error term in the willingness to pay model. As a result, when endogenous behavior variables are included in willingness to pay models their coefficients are inconsistent. One way to obtain consistent estimates is an instrumental variable model. The predicted value from the behavioral model is used as an independent variable in the willingness to pay model. For example, the predicted trips variable from a travel cost demand model could be used in a model of the willingness to pay for site access. The predicted value from a medical utilization model could be used in a model of the willingness to pay for a medical treatment program.

Another approach to obtain consistent estimates is joint estimation of willingness to pay and behavior models. It is conceivable that behavior and willingness to pay will share unobserved factors that determine the variation in each. For example, unobserved tastes may be correlated with both recreation behavior and willingness to pay for a recreation quality improvement. Ignoring this correlation may cause a loss in econometric efficiency. Jointly estimating behavior and willingness to pay models allows for an improvement in econometric efficiency.

In similar research Alberini et al. (1997) describe a jointly estimated willingness to pay and medical utilization model but exclude the medical utilization variable from the willingness to pay model. Minor gains in econometric efficiency are found. Cameron and Englin (1997) model the relationship between respondent knowledge and willingness to pay. Fishing experience is used as a proxy for knowledge and treated as endogenous in a jointly estimated willingness to pay and experience model. The authors find that information is exogenous with respect to the mean of willingness to pay but endogenous with respect to the variance of willingness to pay. This paper expands on these efforts by focusing on the direct effect of changes in recreation behavior on willingness to pay.

In this paper we investigate models of willingness to pay and the behavioral change from a quality improvement with contingent valuation and revealed and stated behavior data.

Respondents are asked for their willingness to pay for a water quality improvement. Then, respondents are asked for the number of recreation trips they took in the past 12 months and the number of trips that they would take during the next 12 months if water quality improved. The change in the number of trips is used as a determinant of willingness to pay. We compare willingness to pay models with the endogenous trip change and predicted trip change as independent variables and a jointly estimated model.

In the rest of this paper we sketch the economic models underlying the valuation and behavior data. We next describe the application of the CVM including the questions and the data. The empirical results are then presented. We conclude with a discussion of our results and some implications for further valuation research. 


\section{THEORETICAL MODEL}

Suppose consumers have the utility function, $u(x, q, z)$, where $x$ is on-site (recreational) use, $q$ is a measure of quality, and $z$ a composite of all market goods. The expenditure function, $e(p, q$, $u$ ), is found by solving the consumer problem: $\min [z+p x]$ s.t. $u=u(x, q, z)$, where $p$ is the ownprice of on-site use and $p_{z}=1$. The expenditure function measures the minimum amount of money a consumer must spend to achieve the reference utility level. Expenditures are increasing in $p$ and $u$ and decreasing in $q$.

Willingness to pay is the maximum amount of money consumers would give up in order to enjoy an improvement in quality. The willingness to pay for the improvement in quality is

$$
\text { WTP }=e(p, q, u)-e\left(p, q^{*}, u\right)
$$

where $q$ is a degraded level of quality and $q^{*}$ is an improved level of quality. Expenditures to maintain the utility level decrease with the increase in quality so that WTP $\geq 0$.

Assume the reference level of utility is $u^{*}=v\left(p, q^{*}, y\right)$, where $y$ is the income and $v(p, q, y)$ the indirect utility function found by solving the problem: $\max [u(x, q, z)]$ s.t. $y=z+p x$. Substitution of the indirect utility function into the willingness to pay function (1) yields the Hicksian variation function

$$
W T P=e\left[p, q, v\left(p, q^{*}, y\right)\right]-y
$$

where WTP is the equivalent variation measure of welfare. According to reasonable assumptions and economic theory, the variation function is increasing (decreasing) in income for $q$ normal (inferior) and increasing with decreases in pre-policy quality, $q$ (Whitehead, 1995).

The effect of the own-price on willingness to pay is

(3)

$$
\frac{\partial W T P}{\partial p}-\frac{\partial e}{\partial p}+\frac{\partial e}{\partial v} \frac{\partial v^{*}}{\partial p}
$$

where $v^{*}=v\left(p, q^{*}, y\right)$. Multiplication of the second term on the right-hand side by $\frac{\partial v^{*} / \partial y}{\partial v^{*} / \partial y}$ and recognizing that $\frac{\partial v^{*}}{\partial y}=\frac{1}{\partial c^{+} / \partial v}$ yields

(4)

$$
\frac{\partial \mathrm{WTP}}{\partial p}=x^{h}(p, q, u)-\theta x^{m}\left(p, q^{*}, y\right)
$$


where $x^{h}(p, q, u)$ is the Hicksian demand, ${ }^{\theta}=\frac{\partial \tau / \partial v}{\partial c^{*} / \partial v}$, and by Roy's identity, $x^{m}(p, q, y)$ the Marshallian demand. Substitution of $v(p, q, y)$ for $u$ provides the link between willingness to pay for the quality improvement and the change in behavior

(5)

$$
\frac{\partial \mathrm{WTP}}{\partial p}=x^{m}(p, q, y)-\theta x^{m}\left(p, q^{*}, y\right)
$$

The effect of the own-price on willingness to pay is a function of the difference in the number of trips with degraded quality and the number of trips with improved quality after adjustment by the differences in the marginal costs of utility across quality levels. The effect of the own-price on willingness to pay is negative for $\theta \rightarrow 1$.

When improved quality is constant the empirical linear willingness to pay model is

WTP $=\alpha_{0}+\alpha_{1} p+\alpha_{2} q+\alpha_{3} y+\mu$

where the coefficient on the own-price is an estimate of the change in the number of trips, $\hat{u}_{1}=\Delta r$, assuming the marginal costs of utility across quality levels approaches 1 . The product of the own-price of recreation and the additional recreation trips, $\alpha_{1} p$, is an estimate of the expenditures on additional trips. Willingness to pay is net of these expenditures.

The linear Marshallian demand functions with degraded and improved qualities are

$x=\beta_{0}+\beta_{1} p+\beta_{2} q+\beta_{3} y+\varepsilon$

(8)

$$
x^{*}=\beta_{0}^{*}+\beta_{1}^{*} p+\beta_{2}^{*} q^{*}+\beta_{3}^{*} y+\varepsilon^{*}
$$

A quality improvement can have direct and indirect effects on demand. The direct effect of quality on demand is a shift in the demand function, $\beta_{2} q^{+}>\beta_{2} q$. Indirect effects are changes in the coefficients on other variables (i.e., $\beta_{1}^{*}+\beta_{1}$ ). In the typical two-dimensional demand diagram the direct effect and indirect effects on variables other than the own-price will shift the demand function and lead to an increase in willingness to pay. The indirect effect of quality on the price coefficient is a change in the slope of the demand function, typically making it more elastic (i.e., $\left|\beta_{1}^{*}\right|>\left|\beta_{1}\right|$ ). This would lead to a counter clockwise rotation of the demand function and an increase in willingness to pay.

The change in demand is $\Delta x=x^{*}-x$. When improved quality is constant, the change in demand is 
(9)

$$
\Delta x=\left(\beta_{0}^{*}-\beta_{0}\right)+\left(\beta_{1}^{*}-\beta_{1}\right) p-\beta_{2} q+\left(\beta_{3}^{*}-\beta_{3}\right) y+\left(\varepsilon^{*}-\varepsilon\right)
$$

Without information on the own-price of recreation we impose the restriction that the elasticity of demand is constant with quality change (i.e., $\beta_{1}^{\dagger}-\beta_{1}$ ). The demand change function reduces to

$$
\Delta x=\left(\beta_{0}^{*}-\beta_{0}\right)-\beta_{2} q+\left(\beta_{3}^{*}-\beta_{3}\right) y+\left(\varepsilon^{*}-\varepsilon\right)=\delta_{0}-\beta_{2} q+\delta_{3} y+v
$$

Proxy variables for travel costs may be used to parameterize the constant term but should not be considered measures of the own-price variable.

Without information on the own-price of recreation, the demand change can be included in the willingness to pay model as a proxy for the own-price

$$
\begin{aligned}
\mathrm{WTP} & =\gamma_{0}+\gamma_{1} \Delta x+\gamma_{2} q+\gamma_{3} y+\mu \\
& =\gamma_{0}+\gamma_{1}\left(\delta_{0}-\beta_{2} q+\delta_{3} y+\nu\right)+\gamma_{2} q+\gamma_{3} y+\mu
\end{aligned}
$$

In this formulation the willingness to pay and demand change error terms may be correlated if the same unobserved factors influence both the change in trips and willingness to pay.

Correlation will cause the change in trips variable and the willingness to pay error term to be correlated, leading to an inconsistent coefficient on the change in trips. Positive correlation will increase the magnitude of the coefficient on demand change while negative correlation will decrease the magnitude.

When the demand change is included in the willingness to pay model the coefficient on the demand change is the marginal willingness to pay for trips, ${ }_{\partial \mathrm{WTP}}=\gamma_{1}$. Since, at the margin, willingness to pay for trips is equal to the own-price the marginal effect of the coefficient on the demand change variable is an estimate of the own-price of recreation.[1]

\section{Empirical model}

Suppose the willingness to pay variable is continuous and censored at zero:

$$
\text { WTP }= \begin{cases}\text { WTP }^{*} & \text { if } \text { WTP }^{*}>0 \\ 0 & \text { if } \text { WTP }^{*} \leq 0\end{cases}
$$

where WTP ${ }^{\star}$ is the latent willingness to pay. In this case the Tobit model is appropriate. Endogeneity of demand change is tested by including the residuals from the demand change 
model, $\hat{V}_{i}$, as an additional independent variable in the independently estimated Tobit willingness to pay model

$$
\mathrm{WTP}_{i}=\gamma_{0}+\gamma_{1} \Delta x_{i}+\gamma_{2} q_{i}+\gamma_{3} y_{i}+\pi \hat{v}_{i}+\mu_{i}^{*}
$$

where $i=1, \ldots, n$. This is a test for whether willingness to pay and the error term from the demand change model are correlated (Wooldridge, 2003). The test for exogeneity is a $t$-test, $\mathrm{HO}: \pi=0$.

An instrumental variable methodology can be used to obtain consistent coefficient estimates. The predicted demand change is included as a regressor in the Tobit model to purge the demand change variable of its error term

$$
\mathrm{WTP}_{i}=\gamma_{0}+\gamma_{1} \Delta \hat{x}_{i}+\gamma_{2} q_{i}+\gamma_{3} y_{i}+\mu_{i}^{* *}
$$

where $\Delta \hat{x}-\hat{\delta}_{0}-\hat{\beta}_{2} q+\hat{\delta}_{3} y$ is the predicted demand change. Additional variables are included in the demand change coefficient vector to serve as the identifying variables. These variables should have high explanatory power in the demand change model and low correlation with willingness to pay and its error term.

Another approach to obtain consistent estimates is to jointly estimate the willingness to pay and behavior model:

$$
\begin{aligned}
& \mathrm{WTP}_{i}=\gamma_{0}+\gamma_{1} \Delta x_{i}+\gamma_{2} q_{i}+\gamma_{3} y_{i}+\mu_{i:} \\
& \Delta x_{i}-\delta_{0}-\beta_{2} q_{i}+\delta_{3} y_{i}+\nu_{i} \rho-\operatorname{corr}\left[\mu_{i}, v_{i}\right]
\end{aligned}
$$

The jointly estimated model is full information maximum likelihood allowing for positive or negative correlation in the normally distributed error terms. The test for the exogeneity in the jointly estimated model is a $t$-test, $\mathrm{HO}: \rho=0$.[2]

Since the willingness to pay model is a Tobit the expected willingness to pay value is a nonlinear function

$$
E(W T P)=\Phi\left(\frac{\gamma^{\prime} \bar{X}}{\sigma}\right)\left(\gamma^{\prime} \bar{X}+\sigma \frac{\phi\left(\gamma^{\prime} \bar{X} / \sigma\right)}{\Phi\left(\gamma^{\prime} \bar{X} / \sigma\right)}\right)
$$

where the mean values of the vector of independent variables, $\bar{X}$, are used, $\Phi(\cdot)$ the standard normal density function, $\Phi(\cdot)$ the standard normal distribution function, and $\sigma$ the standard error 
of the error term.[3] The standard errors for the expected willingness to pay are constructed using the Delta Method (Greene, 1997).

\section{DATA}

In order to evaluate the benefits of improved water quality in the Neuse River, North Carolina, information was collected in 1998 through a stratified, random sample telephone survey of over 1000 landowners from across 12 counties of the Neuse River basin (Hoban and Clifford, 1999).[4] The survey was not designed to collect travel cost information for two reasons. First, there would be a limited amount of variation in the travel cost due to a limited variation in distance from the resource site. Second, the cost of a series of questions focused on defining access sites and eliciting the choice of access sites was prohibitive. Therefore we have no precise information on the distance from the respondents' home to the Neuse River so that the own-price variable can only be measured with considerable error.

The survey response rate, measured as completions divided by the sum of completions and refusals, is $75 \%$. The sample includes $41 \%$ farm and $59 \%$ non-farm landowners. Forty percent are from the upper, 33\% are from the middle, and 27\% are from the lower Neuse River basin. After deleting outliers with unrealistically high increases in trips with water quality improvements the empirical analysis is conducted with 991 observations.[5] All summary statistics and empirical results are weighted to reflect the geographic and farm/non-farm stratification of the sample.

Survey respondents are presented with the contingent valuation scenario: "We already pay for government environmental programs through taxes, water bills, and other means. However, government will need more money if water quality in the Neuse River is to be protected. This money would pay for government programs to control pollution, monitor water quality, protect fish habitat, and educate people about ways to reduce pollution. The goal would be to make sure water quality in the Neuse River is safe enough for fishing, swimming, and drinking treated water from the River."

The valuation question presents respondents with a hypothetical situation: "Would you and your household be willing to pay $\$ A$ each year for these programs, if you knew the money would be used to make sure water quality in the Neuse River is safe?" The starting dollar amount (\$A) took on nine values with a random start ranging from $\$ 10$ to $200(10,25,50,75,100,125,150$, $175,200)$. The starting points and iteration ranges were pre-tested to determine if the starting point range covered the expected range of willingness to pay.

Respondents are asked follow up questions with the next highest or lowest dollar amount. When respondents change their answer in response to a change in the price (e.g., yes/no, no/yes) the responses are used to construct upper and lower bounds for individual willingness to pay and the continuous willingness to pay variable is equal to the midpoint between the bounds. For respondents reaching $\$ 10$ or 200 before their willingness to pay is bounded from above and below, the open-ended question is presented: "What is the most that you and your household 
would be willing to pay each year for these programs?" With open-ended willingness to pay questions, willingness to pay is explicitly revealed (e.g., a survey respondent may answer "\$ 300 " in response to this question) and willingness to pay is a continuous variable.[6]

A summary of the data is presented in Table 1. The revealed behavior trip data is gathered with a question before the potential quality improvement is described which elicits the number of outdoor recreation trips (including all activities) taken at the Neuse River during the past twelve months. After the quality improvement is described, a stated behavior question asks for the number of trips that would be taken in the 12-month time period after the quality improvement. Twenty-seven percent of the sample participates in Neuse River recreation. The average number of trips with degraded quality, TRIPS1, is 3.21. Forty-eight percent state that they would participate in recreation with the water quality improvement illustrating that non-users become users with the improvement. The average number of trips with improved quality, TRIPS2, is 5.48. The difference between these values is NEWTRIPS. The average number of additional household recreation trips is 2.27 .

Table 1

Data summary

\begin{tabular}{lrrcr}
\hline Variable & Mean & S.D. & Minimum & Maximum \\
\hline MAXWTP & 77.25 & 87.23 & 0 & 750 \\
TRIPS 1 & 3.21 & 17.52 & 0 & 365 \\
TRIPS2 & 5.48 & 19.09 & 0 & 365 \\
\$A & 102.96 & 63.52 & 10 & 200 \\
INCOME (\$ 1000s) & 73.27 & 57.66 & 2.5 & 200 \\
UPPER & 0.63 & 0.48 & 0 & 1 \\
MIDDLE & 0.28 & 0.45 & 0 & 1 \\
NOTSAFE & 0.25 & 0.43 & 0 & 1 \\
BOATABLE & 0.36 & 0.48 & 0 & 1 \\
TALKSOME & 0.66 & 0.47 & 0 & 1 \\
WQWORSE & 0.64 & 0.48 & 0 & 1 \\
Sample & 991 & & & \\
\hline
\end{tabular}

The average willingness to pay, MAXWTP, is $\$ 77$. Sixty-nine percent of the sample has a positive willingness to pay. Of these $69 \%, 30 \%$ did not take any recreation trips during the past 12 months and 55\% would not take any recreation trips after the water quality improvement. Therefore, $45 \%$ of those with a positive willingness to pay have no intention of participating in recreation on the Neuse River. These respondents are considered to have total value (i.e., willingness to pay) equal to non-use value. Those respondents with positive trips are considered to have total value composed of both use value and non-use value.

The average dollar amount presented to respondents in the willingness to pay question, $\$ A$, is $\$ 103$. The household income variable, INCOME, is measured in thousands of 1998 dollars. The average income is $\$ 73,270$.[7] Sixty-three percent of the sample lives in the upper Neuse River basin, UPPER. Twenty-eight percent lives in the middle Neuse River basin, MIDDLE. 
To elicit quality perceptions, respondents are asked whether they considered water quality in the Neuse River to be safe for boating, fishing, swimming, and drinking. NOTSAFE is equal to 1 if respondents feel that the Neuse River is not safe for boating, fishing, and swimming. Twentyfive percent of the sample considered the Neuse River to not be safe. BOATABLE is equal to 1 if respondents feel that Neuse River water quality is safe for boating and equal to 0 if respondents feel that water quality is not safe for swimming or fishing. Thirty-six percent of the sample considered the Neuse River to be safe for boating.

Respondents are asked whether they felt that water quality in the Neuse River has gotten better, worse, or stayed the same during the past 5 years. WQWORSE is equal to 1 if respondents feel that water quality has gotten worse. Sixty-four percent of the sample feels that water quality is worse. TALKSOME is a dummy variable equal to 1 if respondents talk about the Neuse River and its water quality problems with others and measures information about the river. Sixty-six percent of the sample has discussed the Neuse River.

\section{RESULTS}

The willingness to pay model should include measures of $p, q$ and $y$. Since NEWTRIPS is nonnormally distributed, the natural log of NEWTRIPS (LNNEW $=\ln [$ NEWTRIPS +1$]$ ) is used as a proxy for own-price. The log of NEWTRIPS should be positively related to willingness to pay. The MIDDLE and UPPER dummy variables are included to account for distance from the lower Neuse River, the region that supports a wider variety and higher quality of recreational resources. If these dummy variables serve as measures of the own-price of recreation then they should have a negative effect on willingness to pay. If water quality is a normal (inferior) good, MAXWTP should increase (decrease) with INCOME. NOTSAFE is a measure of the perceived water quality without the program, $q$, and should have a positive effect on willingness to pay. We include the dollar amount, $\$ A$, to test for starting point bias.

The demand change model should also include measures of $p, q$ and $y$. MIDDLE and UPPER are included as proxy variables for own-price. If they are good measures of own-price then they should have a negative effect on the demand change. The variables BOATABLE and NOTSAFE are measures of the perceived water quality and should be positive. WQWORSE and TALKSOME should have a positive effect on the demand change.

As recommended by Wooldridge (2003) we include all of the exogenous variables in the demand change equation. This explains the appearance of the tax amount as an explanatory variable for the demand change. BOATABLE, TALKSOME and WQWORSE are used as identifying variables. Each of these variables has low explanatory power in the willingness to pay model $(P>0.10)$.

Three Tobit models are presented in Table 2: the independently estimated MAXWTP model including the potentially endogenous LNNEW (Model 1), the independently estimated MAXWTP and LNNEW models with predicted LNNEW, P_LNNEW (Model 2), and the jointly estimated MAXWTP and LNNEW model (Model 3). 
Tobit willingness to pay and OLS demand change models

\begin{tabular}{|c|c|c|c|c|c|c|c|c|c|c|}
\hline \multirow[t]{4}{*}{ Variable } & \multicolumn{6}{|c|}{ Independently estimated } & \multirow{2}{*}{\multicolumn{4}{|c|}{$\frac{\text { Jointly estimated }}{\text { Model } 3}$}} \\
\hline & \multirow{2}{*}{\multicolumn{2}{|c|}{$\begin{array}{l}\text { Model } 1 \\
\text { Willingness to pay } \\
\text { (MAXWTP) }\end{array}$}} & \multicolumn{4}{|l|}{ Model 2} & & & & \\
\hline & & & \multicolumn{2}{|c|}{$\begin{array}{l}\text { Willingness to pay } \\
\text { (MAXWTP) }\end{array}$} & \multicolumn{2}{|c|}{$\begin{array}{l}\text { Demand change } \\
\text { (LNNEW) }\end{array}$} & \multicolumn{2}{|c|}{$\begin{array}{l}\text { Willingness to } \\
\text { pay (MAXWTP) }\end{array}$} & \multicolumn{2}{|c|}{$\begin{array}{l}\text { Demand change } \\
\text { (LNNEW) }\end{array}$} \\
\hline & Coefficient & $t$-Ratio & Coefficient & $t$-Ratio & Coefficient & $t$-Ratio & Coefficient & $t$-Ratio & Coefficient & $t$-Ratio \\
\hline Constant & -24.74 & -1.66 & -84.73 & -3.32 & 0.72 & 5.70 & -84.95 & -3.01 & 0.72 & 6.00 \\
\hline SA & 0.34 & 5.92 & 0.35 & 6.03 & -0.0002 & -0.37 & 0.35 & 5.22 & ${ }^{-} 0.0002$ & -0.37 \\
\hline INCOME & 0.26 & 4.15 & 0.22 & 3.43 & 0.001 & 1.06 & 0.22 & 3.22 & 0.001 & 1.03 \\
\hline UPPER & 23.06 & 1.73 & 65.34 & 3.30 & -0.73 & -7.31 & 65.67 & 3.04 & -0.73 & -9.48 \\
\hline MIDDLE & 7.46 & 0.53 & 40.38 & 2.21 & -0.60 & -5.70 & 41.07 & 2.03 & -0.60 & -7.51 \\
\hline NOTSAFE & -20.55 & -2.41 & -28.75 & -3.15 & 0.30 & 4.12 & -29.20 & -2.86 & 0.30 & 4.03 \\
\hline LNNEW & 25.93 & 6.48 & & & & & 76.73 & 3.73 & & \\
\hline P_LNNEW & & & 77.23 & 4.35 & & & & & & \\
\hline BOATABLE & & & & & 0.25 & 3.81 & & & 0.26 & 3.75 \\
\hline TALKSOME & & & & & 0.26 & 4.19 & & & 0.26 & 3.66 \\
\hline WQWORSE & & & & & 0.16 & 2.56 & & & 0.16 & 2.58 \\
\hline$\sigma$ & 109.10 & 34.55 & 110.42 & 34.51 & & & 108.53 & 54.03 & & \\
\hline$\rho[v, \varepsilon]$ & & & & & & & & & -0.40 & -2.52 \\
\hline LL function & -444 & & & & 86.32 & & & & 76.61 & \\
\hline Sample & 99 & & & & 91 & & & & 91 & \\
\hline
\end{tabular}

In the independently estimated Model 1 the tax amount, income, and the log of the demand change are positively related to willingness to pay. The tax amount result indicates that starting point bias is present. The income result indicates that water quality is a normal good. The demand change result indicates that more frequent users of the Neuse River are willing to pay more. Willingness to pay of respondents in the upper Neuse River basin is greater than those in the lower Neuse River basin. This result indicates that the regional dummy variable is not a proxy for price but is a taste variable. Willingness to pay decreases if respondents feel that Neuse River water quality is not safe. This is the opposite of the expected sign. One explanation is that these respondents feel that the water quality goal is beyond reach and reject the premise of the contingent market. In other words, these respondents may be "protest bidders".[8]

In a separate independently estimated willingness to pay model, the error term from the demand change model is included as an additional independent variable to test for exogeneity of the demand change variable. The coefficient on this variable is negative and statistically significant ( $\pi=-53.64, P=0.01)$ indicating that demand change is an endogenous variable.

In the independently estimated demand change model, the change in demand with the water quality improvement increases for respondents who perceive that current water quality is only boatable or not safe. The demand change decreases if the respondent lives in the middle or upper Neuse River basin indicating that these variables serve as a proxy for the own-price of recreation. Those who talk about the Neuse River and feel that water quality has gotten worse state that they would take more trips with a water quality improvement.[9]

The coefficients on P_LNNEW in Model 2 and on LNNEW in Model 3 are three times greater than the coefficient on LNNEW in Model 1. In Models 2 and 3, the coefficients on the MIDDLE dummy variables are positive and significantly different from zero. All other qualitative results in Models 2 and 3 are the same as in Model 1. In the jointly estimated Model 3, the correlation in the error terms between the MAXWTP and LNNEW models is $\rho=-0.40$. This correlation is 
significantly different from zero $(P=0.01)$. The negative correlation explains why the coefficient on LNNEW in Model 1 is significantly lower than the coefficient on LNNEW in Model 3. The jointly estimated model produces only modest efficiency gains in coefficient estimates.

The consequences of the misspecification of the willingness to pay model are illustrated in Table 3. Expected willingness to pay is estimated in two ways. First, willingness to pay is estimated at the means of all of the variables, including the log of the change in trips. Second, the log of the change in trips is set equal to zero. The first willingness to pay estimate is a measure of the total value of the quality improvement. The second willingness to pay estimate is a measure of the non-use value of the quality improvement. The difference between the two estimates is an estimate of the use value of the quality improvement.

Table 3

Willingness to pay estimates

\begin{tabular}{|c|c|c|c|c|c|c|}
\hline \multirow[t]{3}{*}{ Willingness to pay } & \multicolumn{4}{|c|}{ Independently estimated } & \multirow{2}{*}{\multicolumn{2}{|c|}{$\frac{\text { Jointly estimated }}{\text { Model } 3}$}} \\
\hline & \multicolumn{2}{|l|}{ Model 1} & \multicolumn{2}{|l|}{ Model 2} & & \\
\hline & Coefficient & $t$-Ratio & Coefficient & $t$-Ratio & Coefficient & t-Ratio \\
\hline Total value & $\$ 74.61$ & 24.69 & $\$ 75.73$ & 24.77 & $\$ 74.97$ & 21.87 \\
\hline Non-use value $(\Delta x=0)$ & $\$ 62.48$ & 18.81 & $\$ 43.05$ & 6.56 & $\$ 42.41$ & 5.63 \\
\hline Use value & $\$ 12.13$ & 6.76 & \$ 32.68 & 5.15 & $\$ 32.56$ & 4.40 \\
\hline
\end{tabular}

The willingness to pay estimate from each of the Tobit models is about $\$ 75$. In Model 1 with the endogenous demand change, non-use value is $84 \%$ of total value and use value is only $16 \%$ of total value. When the predicted value of trips is included in the willingness to pay models, the contribution of use value rises to $43 \%$ of total value in both Model 2 and Model 3 . The differences in use value between Model 1 and Model 2 and Model 1 and Model 3 are statistically significant at the $P=0.05$ level. The contribution of additional trip value to willingness to pay is biased downward when the willingness to pay model includes the endogenous change in trips variable.

The use value is about $\$ 33$ in Models 2 and 3 . Since the predicted number of additional trips is 2.27 , the marginal value of each additional trip is about $\$ 15$. Considering that the marginal value of additional trips is equal to the own-price (i.e., travel cost) of trips, the marginal value estimate appears reasonable.

\section{CONCLUSIONS}

Empirical models of willingness to pay should include exogenous measures of the potential use of the resource such as the own-price of recreation. Oftentimes, measures of the own-price are not available or are measured with significant error. In these cases it is possible to include measures of behavior to proxy for the own-price variable. In this paper we include a measure of 
the demand change induced by water quality improvement as a proxy for the own-price of recreation in a model of the willingness to pay for a quality improvement. We employ an instrumental variable model and a jointly estimated model to test for the appropriate specification. Models that do not account for the endogeneity of the demand change produce biased coefficient estimates.

This approach is useful in a wide variety of valuation applications and under realistic conditions. Omission of own-price variables in willingness to pay models is common. This can be due to measurement error or difficulty in defining travel distance or the opportunity cost of time. Travel distance is difficult to measure when there are a large number of access points for recreation. For example, when air quality improvements lead to increases in time spent outdoors, the large number of outdoor recreation sites requires aggregation of sites. This aggregation would lead to measurement error that can be mitigated by including the change in the number of trips as a proxy variable. The instrumental variable approach should also be used whenever an endogenous behavior variable is included in willingness to pay models. For example, in a willingness to pay model of hunting the daily bag is likely to depend on skill and experience. The error term in an empirical household production model of the daily bag is possibly correlated with the error term in the willingness to pay model.

Future contingent valuation research should explore alternative approaches to combining willingness to pay and behavior data. Efforts in this direction will provide additional evidence of the validity of the contingent valuation method. Data requirements for this approach include variables typically used in contingent valuation studies and others. Willingness to pay, ownprice, cross-price, quality, income, and other variables related to willingness to pay are needed. Variables measuring behavior and behavioral change are also needed.

\section{NOTES}

1 Thanks to an anonymous referee for pointing this out.

2 The model is developed in Smith and Blundell (1986) and estimated with the LIMDEP econometric software (Greene, 2003). See Dickie and Gerking (1996) for an application.

3 Consistent with theory, we impose the implicit property rights that quality must be purchased. The expected value of observed willingness to pay is therefore preferred to the expected value of latent willingness to pay.

4 A map of the Neuse River can be found at the website: http://www.bae.ncsu.edu/programs/extension/wqg/neuse/maps.html.

5 The increase in the number of trips for the six outliers are $\Delta x=58,74,100(n=2), 200$ and 345. 
6 Measuring willingness to pay as a continuous variable should be contrasted with an alternative approach that uses each of the yes or no valuation responses (i.e., iterative data) in a panel data model. [Whitehead, 2002] and [Whitehead, 2004] shows that follow-up valuation questions are not incentive compatible and are prone to starting point bias. The effect of incentive compatibility is to bias willingness to pay estimates downward. Since the purpose of this paper is to illustrate joint estimation with relatively straightforward models, we do not pursue joint estimation with the more complicated random effects model and iterative data. Therefore, the willingness to pay estimates should be considered as downward biased estimates of the value of water quality improvements.

7 Missing income data are imputed from a wage equation used to estimate the determinants of income. The model is run with 785 cases and is specified with the standard variables including education, experience, race and gender. Dummy variables are included for the farm sample and respondents who lived in a city. The dependent variable is the log of income. Missing income data are replaced with the midpoint of the income interval closest to the conditional mean.

8 The empirical results do not change if the protest bidders are deleted.

9 The identifying variables, BOATABLE, TALKSOME, and WQWORSE, are not correlated with the willingness to pay error term from Model 2.

\section{REFERENCES}

Alberini, A., Cropper, M., Fu, T.-T., Krupnick, A., Liu, J.-T., Shaw, D., Harrington, W., 1997. Valuing health effects of air pollution in developing countries: the case of Taiwan. Journal of Environmental Economics and Management 34, 107-126.

Cameron, T.A., Englin, J., 1997. Respondent experience and contingent valuation of environmental goods. Journal of Environmental Economics and Management 33, 296-313.

Champ, P.A., Flores, N.E., Brown, T.C., Chivers, J., 2002. Contingent valuation and incentives. Land Economics 78, 591-604.

Dickie, M.T., Gerking, S., 1996. Formation of risk beliefs joint production and willingness to pay to avoid skin cancer. The Review of Economics and Statistics 78, 451-464.

Greene, W.H., 1997. Econometric Analysis, 3rd ed. Prentice-Hall, Upper Saddle River, NJ. Greene, W.H., 2003. LIMDEP, Version 8.0: User's Manual. Econometric Software, Bellport, NY.

Hoban, T.J., Clifford,W.B., 1999. Landowners' knowledge, attitudes, and behavior in the Neuse River watershed. Final Report to the United States Environmental Protection Agency and the North Carolina Department of Environment and Natural Resources, Raleigh, NC.

Huang, J.-C., Haab, T.C., Whitehead, J.C., 1997. Willingness to pay for quality improvements: should revealed and stated data be combined? Journal of Environmental Economics and Management 34, 240-255. 
Kinnell, J., Lazo, J.K., Epp, D.J., Fisher, A., Shortle, J., 2002. Perceptions and values for preventing ecosystem change: Pennsylvania duck hunters and the Praire pothole region. Land Economics 78, 228-244.

McConnell, K.E., 1990. Models for referendum data: the structure of discrete choice models for contingent valuation. Journal of Environmental Economics and Management 18, 19-34.

Mitchell, R.C., Carson, R.T., 1989. Using Surveys to Value Public Goods: The Contingent Valuation Method. Resources for the Future, Washington, DC.

Seller, C., Chavas, J.-P., Stoll, J.R., 1986. Specification of the logit model: the case of valuation of nonmarket goods. Journal of Environmental Economics and Management 13, 382-390.

Smith, R., Blundell, R., 1986. An exogeneity test for a simultaneous equation Tobit model with an application to labor supply. Econometrica 54, 679-685.

Stewart, J.M., O'Shea, E., Donaldson, C., Shackley, P., 2002. Do ordering effects matter in willingness-to-pay studies of health care? Journal of Health Economics 21, 585-599.

Whitehead, J.C., 1995.Willingness to pay for quality change: comparative statics and theoretical interpretations of empirical results. Land Economics 71, 207-215.

Whitehead, J.C., 2002. Incentive incompatibility and starting point bias in iterative valuation questions. Land Economics 78, 285-297.

Whitehead, J.C., 2004. Incentive incompatibility and starting point bias in iterative valuation questions: reply. Land Economics 80, 316-319.

Whynes, D.K., Frew, E., Wolstenholme, J.L., 2003. A comparison of two methods for eliciting contingent valuations of colorectal cancer screening. Journal of Health Economics 22, 555-574.

Wooldridge, J.M., 2003. Introductory Econometrics: A Modern Approach, 2nd ed. SouthWestern, Mason, $\mathrm{OH}$. 